Nigerian Journal Of Physiological Sciences 21 (1-2): 1-4@Physiological Society Of Nigeria, 2006.

Available online/abstracted at http://www.biolineinternational.org.br/njps; www.ajol.info/journals.njps; www.cas.org

\title{
COMPARATIVE EFFECT OF CAROTENOID COMPLEX FROM GOLDEN NEO-LIFE DYNAMITE (GNLD) AND CARROT EXTRACTED CAROTENOIDS ON IMMUNE PARAMETERS IN ALBINO WISTAR RATS
}

\author{
V. S. EKAM, E. O. UDOSEN and A. E. CHIGBU \\ Department of Biochemistry, College of Medical Sciences, \\ University of Calabar, Calabar, Nigeria. E-mail: ekvisa@yahoo.com
}

\begin{abstract}
Summary: The immunomodulatory effect of Carotenoid complex from Golden Neo-Life Dynamite (GNLD) and carrot extracted Carotenoid was assessed using 24 albino Wistar rats. The rats were assigned to 4 groups of 6 rats each consisting of group 1(control group treated with distilled water), group 2 (treated with olive oil), group 3 (treated with carrot extract + olive oil) and group 4 (treated with GNLD Carotenoid complex + olive oil). The concentration of carrot extracted Carotenoid and that of the GNLD Carotenoid complex were $559 \mathrm{mg} / \mathrm{kg}$. The animals were sacrificed after 21 days of treatment and whole blood collected for analysis of immune parameters. The parameters included; percentage lymphocytes, percentage eosinophils, percentage monocytes and platelet count. There were significant increases $(\mathrm{P}<0.05)$ in groups 3 and 4 which received carrot extract and Carotenoid complex supplement when compared to group 1 and 2 which received distilled water and olive oil. This supports the claim that Carotenoids have immunomodulatory effects. However, it is clear that there were significant increases $(\mathrm{P}<0.05)$ in percentage lymphocytes (40.15 \pm 1.33$)$, monocytes $(2.50 \pm 1.31)$, neutrophils $(60.08 \pm 2.06)$ and platelet count (7.91 \pm 0.53 ) in group 4 which received carotenoid complex when compared to that of group 3 which received carrot extract; lymphocytes $(33.01 \pm 3.20)$, monocytes $(1.52 \pm 0.52)$, neutrophils $(60.12 \pm 1.50)$ and platelet count $(7.81 \pm 0.52)$. These significant increases $(\mathrm{P}<0.05)$ show that both carotenoids have immunomodulatory effects; and that the GNLD Carotenoid complex which consists of alpha-carotene, beta-carotene, lutein, Zeaxanthin, beta-cryptoxanthin, lycopene and alpha-tocopherol is more potent in its immunomodulatory effect compared to the carrot extracted carotenoid which contained mostly alphacarotene and beta-carotene alone.
\end{abstract}

Key Words: Carotenoids, Carrot, immunomodulatory effect, GNLD, white blood cells, platelet count

\section{Introduction}

Carotenoids are widely distributed naturally occurring pigments responsible for the yellow, orange and red color of fruits, roots, flowers, fish, invertebrates and birds. They also occur in algae, bacteria, moulds and yeasts (Watson, 2000). They constitute a class of over 600 natural compounds occurring predominantly in fruits and vegetables. Some carotenoids such as betacarotene are provitamin A compounds that can be converted into vitamin A in vivo. Betacarotene is the most abundant carotenoid and is found notably in orange colored vegetables and fruits and in dark green leafy vegetables including carrots, pumpkin, winter squash, sweet potatoes, apricots, mangoes, kale, spinach and collard greens (Steinmetz and potter; 1996).
Many carotenoids are potent antioxidants enabling them to neutralize free radicals generated as by-products of oxidative metabolism in the body or derived from exogenous sources. Free radicals can attack and damage RNA and DNA in cells as well as inactive proteins and enzymes by reactions with amino acids. They have also been shown to be anticarcinogens in rats and mice and may be anticarcinogens in humans (Singh and Lippman, 1998). There are other biological functions of carotenoids that may be involved in cancer prevention. Some of these (beta-carotene, canthalxanthin, lutein, lycopene, and alphacarotene) have been found to up-regulate gap junctional intracellular communication via 
changes in gene expression (Zhang et al, 1992). Furthermore alpha carotene and beta-carotene may inhibit cell proliferation and beta-carotene may enhance immune function.

Carotenoids are generally known to be precursors of vitamin A, but apart from acting as a precursor, it is equally essential in the body in fighting against disease and infection. In most developing countries, people do not really have an understanding of the roles played by carotenoids. It has been observed generally that people do not really incorporate fruits and vegetables into their diet, probably because they do not have an understanding of the nutritional value of fruits. Diseases like heart diseases, cataracts, cancer, macular degeneration can be minimized if enough carotenoids are incorporated into the diet.

The objective of this study was to investigate the effects of supplementation of carrot extracted carotenoid (containing a high content of alpha-carotene and beta carotene) as well as a commercial carotenoid complex from GNLD ( containing carrot extract, apricot, red bell pepper extract, straw berry concentrate, peach concentrate, lycopene, lutein, zeaxanthin, D-alpha tocopherol) on some immune functions of albino wistar rats.

\section{Materials and Methods}

The carrots used for this research were purchased from the Marian market in Calabar, Nigeria. They were chopped into smaller pieces with a knive and dried in an Astell-Hearson oven to a constant weight at $50^{\circ} \mathrm{C}$ and then grounded into powder using an electric blender. The carotenoid in the ground carrot was extracted using a soxhlet apparatus; $10 \mathrm{~g}$ of the dried extract was dissolved in $40 \mathrm{ml}$ of olive oil, the olive oil serving as an excipient and administered to the rats at a dose of $559 \mathrm{mg} / \mathrm{kg}$. The commercial carotenoid complex supplement was purchased from a GNLD distributor in Calabar. The concentration of carotenoid in each capsule was $900 \mathrm{mg}$; this was dissolved in $40 \mathrm{ml}$ of olive oil and administered at an oral dose of $559 \mathrm{mg} / \mathrm{kg}$ body weight.

Twenty four male wistar albino rats weighing between 150 and $200 \mathrm{~g}$ used were divided into four groups of six rats each and kept in plastic cages, they were fed with rat pellets and water ad libitum. The experimental group and treatment included; group 1(control), group 2(treated with olive oil), group 3(carrot extract with olive oil), group 4 (GNLD carotenoid complex with olive oil). The administration was done orally and lasted for twenty one days after which the rats were sacrificed by suffocation using chloroform after an overnight fast. The blood obtained by cardiac puncture was stored in heparinized vials and used for analysis of hematological indices.

Differential white cell count:

These were estimated using the method of Osim et al (2004). A dry micropipette was used to suck in blood from the blood sample bottle , a small drop of blood was applied to one end of a slide and quickly placed on the bench holding it in position ; the end of the second slide was then placed in the drop and held there until the blood had spread across it. It was then drawn slowly over the whole length of the first slide being held at an angle of $45^{\circ}$.

After the blood had spread, it was dried before staining, with feishman's stain. The film was washed off in a gentle stream of water dried with filter paper and examined under low and high power microscope and the different kinds of cells counted.

\section{Neutrophils}

These cells are 10-12 $\mu \mathrm{m}$ in diameter; the cytoplasm is granular and is faintly lilac stained. The granules are very fine, uniform and pink in color. The nucleus is stained blue and consists of 2-5 lobes joined by thin chromatin threads.

\section{Eosinophils}

These cells are about $10-12 \mu \mathrm{m}$ in diameter; the cytoplasm contains large round reddish or orange granules which are closely packed. The nucleus is usually bilobed and the lobes are joined by a thick band.

\section{Basophils}

These cells are about 8-10 microns in diameter; the cytoplasm contains a few basophilic granules, which are quite large in size. The nucleus is usually bilobed or kidney shaped and the granules frequently obscure the nucleus.

\section{Monocytes}

These are the largest cells, measuring between $16-22 \mu \mathrm{m}$ in diameter. They have one large nucleus, which is usually centrally placed within the cell and often kidney shaped. The cytoplasm staining pale, grayish-blue.

\section{Lymphocytes}

Small lymphocytes: These have a diameter of $9-10 \mu \mathrm{m}$ and have a round, deep purple staining nucleus, which occupies most of the 
cells so that the cytoplasm, which stains a blue colour, can be seen only as a rim around the nucleus.

Large lymphocytes:

These are thought to be young lymphocytes. They are between $12-15 \mu \mathrm{m}$ in diameter, the nucleus staining a little paler than the small lymphocytes. The cytoplasm is more plentiful, staining a pale blue colour.

\section{Platelet count}

This was estimated from heparinized blood by the method of Osim et al (2004).This involves microscopic visual identification and counting of platelets in Rees and Ecker solution in the middle square of the Neubauer's chamber.

Table 1: Differential white blood cell count of albino wistar rats treated with carrot extracted Carotenoid as well as Carotenoid complex from GNLD

\begin{tabular}{ccccccc}
\hline Group & Treatment & $\begin{array}{c}\text { Lymphocytes } \\
\%\end{array}$ & $\begin{array}{c}\text { Eosinophils } \\
\%\end{array}$ & $\begin{array}{c}\text { Monocytes } \\
\%\end{array}$ & $\begin{array}{c}\text { Neutrophils } \\
\%\end{array}$ & $\begin{array}{c}\text { Platelets } \\
\left(\mathrm{mm}^{3}\right)\end{array}$ \\
\hline 1 & Distilled water & $28.12 \pm 1.40$ & $1.25 \pm 0.50$ & $1.25 \pm 0.50$ & $54.01 \pm 3.30$ & $7.03 \pm 0.51$ \\
2 & Olive oil & $28.52 \pm 1.47$ & $1.25 \pm 0.52$ & $1.18 \pm 0.51$ & $55.00 \pm 4.06$ & $7.36 \pm 0.41$ \\
3 & $33.01 \pm 3.20^{\mathrm{a}}$ & $1.75 \pm 0.48$ & $1.52 \pm 0.52$ & $60.12 \pm 1.50^{\mathrm{a}}$ & $7.81 \pm 0.25^{\mathrm{a}}$ \\
& $\begin{array}{c}\text { Carrot } \\
\text { Extract }+ \\
\text { Olive oil } \\
\text { GNLD } \\
\text { Carotenoid } \\
\text { complex }+ \\
\text { Olive oil }\end{array}$ & $40.15 \pm 1.33^{\mathrm{a}}$ & $1.50 \pm 0.50$ & $2.50 \pm 1.30^{\mathrm{a}}$ & $60.08 \pm 2.06^{\mathrm{a}}$ & $7.91 \pm 0.53^{\mathrm{a}}$ \\
& & & & & \\
\hline & & & & & \\
\hline & Values are mean $\pm s d$, a s=significant increase $(P<0.05)$ compared to the controls (Groups 1\&2)
\end{tabular}

\section{Results}

Results of the differential white blood cell and platelet counts measured in healthy albino wistar rats treated with carrot extract, commercially produced Carotenoid complex from GNLD as well as distilled water for the control group are presented in table 1. From the table it is obvious that there were significant increases $(\mathrm{p}<0.05)$ in \% lymphocyte counts in groups $3(33.01 \pm 3.20)$ and $4(40.15 \pm 1.33)$ which received carrot extract + olive oil and GNLD Carotenoid complex + Olive oil compared to the control $(28.12 \pm 1.40)$; however the result for group 2 that received olive oil alone $(28.52 \pm 1.47)$ was similar to that of the control group. There was a significant increase $(\mathrm{p}<0.05)$ in $\%$ monocytes count in group 4 which received Carotenoid complex + Olive oil $(2.50 \pm 1.32)$ when compared to that of the control $(1.25 \pm$ $0.50)$.

As shown in the table above, there were no significant differences ( $p>0.05)$ in eosinophils (\%) in group 2,3 and 4 which received olive oil $(1.25 \pm 0.52)$, carrot extract + olive oil $(1.75 \pm$ $0.48)$ and Carotenoid complex supplement + olive oil $(1.50 \pm 0.50)$ compared to the control $(1.25 \pm 0.50)$ group.

\section{Discussion}

From Table 1, there were significant increases $(\mathrm{p}<0.05)$ in \% lymphocyte counts in groups $3(33.01 \pm 3.20)$ and $4(40.15 \pm 1.33)$ which received carrot extract + olive oil and GNLD Carotenoid complex + Olive oil compared to the control $(28.12 \pm 1.40)$; however the result for group 2 that received olive oil alone $(28.52 \pm 1.47)$ was similar to that of the control group. The observed increase in lymphocyte proliferation in both Carotenoid treated groups may be related to the chemical composition of both Carotenoid complexes; as the significantly higher value in the GNLD Carotenoid complex may be due to the presence of !-carotene, ßcarotene, lutein, Zeaxanthin, ß-crptoxanthin, lycopene and !-tocopherol compared to the carrot extract group that contained ! -carotene and B-carotene alone. Lymphocyte proliferation is a common parameter which has been measured in several studies investigating the 
immunomodulatory effects of ß-carotene (Gossage, 2000).

There was a significant increase $(\mathrm{p}<0.05)$ in $\%$ monocytes count in group 4 which received Carotenoid complex + Olive oil $(2.50 \pm 1.32)$ when compared to that of the control (1.25 \pm $0.50)$. The increase in $\%$ monocyte count may be as a result of prevention of oxidation of cellular lipids by the Carotenoids, as the Carotenoid complex may help to lessen cellular damage that may lead to disease. This finding is important because oxidation contributes to aging, decline in immune system and chronic diseases such as heart disease, cancer, degenerative diseases of the eyes (cataract, macular degeneration) and degenerative diseases of the nervous system (Gossage, 2000).

There were significant increases $(\mathrm{p}<0.05)$ in neutrophil counts (\%) in groups 3 and 4 which received carrot extract + olive oil $(60.12 \pm 1.50)$ and Carotenoid complex supplement (60.08 \pm 2.06) when compared to that of the control

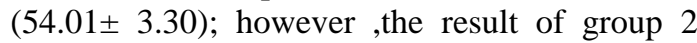
which received olive oil $(55.00 \pm 4.06)$ was similar to that of the control. This increase may be as a result of the fact that !-carotene, ßcarotene and $ß$-cryptoxanthin can be converted to retinol or vitamin $\mathrm{A}$ which can further be converted to more active retinoids. Retinoids are essential for the growth and maturation of many epithelial cells as well as white blood cells such as neutrophils (lampen, 2000).

The result of the study also shows a significant increase $(\mathrm{p}<0.05)$ in platelets count $\left(\mathrm{mm}^{3}\right)$. In group 3 and 4 which received Carotenoid complex supplement $(7.91 \pm 0.53)$ and carrot extract $(7.81 \pm 0.25)$ compared to the control $(7.03 \pm 0.51)$. This result agrees with the literature reports that antioxidants interfere with initiation and propagation of free radical actions and this can protect membranes from free-radical induced oxidative damage (Burton et al, 1990). Free radicals are known to attack and destroy body proteins, polyunsaturated fats and DNA. When these Carotenoids are complexed with free radical their availability and functioning ability are thus reduced.

\section{Conclusion}

This study has shown the effect of carrot extract (! - and ß- carotene) and commercially produced Carotenoid complex supplement from GNLD containing carrot extract, apricot, red bell pepper extract, strawberry concentrate, peach concentrate, lycopene, lutein, zeaxanthin, d-alpha tocopherol on albino wistar rats. It shows that Carotenoids supplement or those in carrots can boost the body's immunity and also that the GNLD Carotenoid complex boosted immunity more than that in the carrot extract alone. The non-significant differences in the various parameters seen in groups 1 and 2 which received distilled water and live oil respectively shows that the olive oil had no significant effect on the results and that the results obtained in groups 3 and 4 were due to the administered Carotenoid and carrot extract alone. I therefore suggest that diets rich in Carotenoids like carrot, red bell pepper, tomato, spinach, apricot, strawberry, water melon, carica papaya (pawpaw), and citrus vinifera (tangerine) be consumed since they contain high Carotenoid content that is able to boost the body's immunity especially by people in poor countries who cannot afford the GNLD Carotenoid complex.

\section{References}

Gossage, E. 2000. Effect of ß-carotene supplementation and lactation on Carotenoid metabolism and mitogenic Tlymphocyte proliferation. Am. J.Clin. Nutri. 71: 950-955

Lampen, A. 2000. Ultraviolet light-induced reductions in plasma Carotenoid levels. Am. J.Clin. Nutri.47:879

Osim E.E, Akpogomeh B.A, Ibu J.O ,Eno A.E.,2004 Experimental Physiology Manual, Department of Physiology University of Calabar,Calabar. $3^{\text {rd }}$ ed :6081.

Singh, D.K. and Lippman, S.M. 1998. Cancer chemoprevention: Retinoids, Carotenoids and other classic antioxidants, Oncology 2:1643-1648

Steinmetz, K.A. and Potter, J.D. 1996. Vegetables, Fruit and Cancer prevention: A Review. J Am Diet. Assoc. 96:1027

Watson, R. R. 2000. Effects of Beta Carotene on Lymphocyte subpopulation in elderly humans. Clin. Nutri. 107-112

Zhang, L. X., Meeker, P. R., Messina, M. 1992. Carotenoids upregulate gene expression independent of their provitamin A or antioxidant properties. Cancer Research. 52,5707

Received: $18 / 9 / 06$

Accepted: 13/10/06 